\title{
ESCOLAS PÚBLICAS MILITARIZADAS COMO FORMA DE VIOLÊNCIA LEGÍTIMA DO ESTADO SOBRE OS ESTUDANTES DA CLASSE TRABALHADORA
}

\author{
MILITARIZED PUBLIC SCHOOLS AS A FORM OF LEGITIMATE STATE \\ VIOLENCE AGAINST WORKING CLASS STUDENTS
}

\author{
Edna Mara Corrêa Miranda ${ }^{1}$
}

\begin{abstract}
RESUMO: O presente estudo tem por objetivos compreender de que forma o Estado exerce a violência legítima nas escolas públicas militarizadas e revelar as contradições entre o discurso de militarização e o cotidiano das escolas já militarizadas. A metodologia constituiu de revisão de dissertações de Mestrado que investigaram as escolas militarizadas para mostrar as contradições reais do que de fato acontece nessas escolas e as Portarias $\mathrm{n}^{\circ}$ or/2019 e $\mathrm{n}^{\circ}$ 09/2019 que consolidaram o projeto Escolas de Gestão Compartilhada, transformando quatro escolas públicas do Distrito Federal em Colégios da Polícia Militar. Como fundamentação, utilizamos a Pedagogia Histórico-crítica e a Teoria Crítica, sobretudo com Bourdieu (sistema de ensino enquanto violência simbólica) e Althusser (aparelhos ideológicos e repressores do Estado). Para compreensão dos conceitos de violência e Estado, buscamos em Weber a sua leitura sobre o Estado Moderno como detentor da violência legítima. O estudo revelou que o Estado exerce violência sobre os estudantes da classe trabalhadora por meio dos aparelhos ideológicos e repressores representados pela escola e pela polícia militar em forma de políticas educacionais; as contradições entre o discurso de militarização e o cotidiano das escolas já militarizadas revelam o alinhamento às políticas educacionais neoliberais.
\end{abstract}

Palavras-chave: Militarização das escolas públicas. Violência. Estado Moderno. Aparelho Ideológico do Estado. Aparelho Repressor do Estado.

ABSTRACT: The present study aims to understand how the State exercises violence in militarized public schools and to reveal the contradictions between the militarization

\footnotetext{
I Aluna do Programa de Pós-Graduação em Educação/ Mestrado - Modalidade Profissional- PPGEMP da Universidade de Brasília- UnB. Licenciada em Pedagogia e Filosofia. Especialização em Psicopedagogia e Orientação Educacional. Grupo de Pesquisa: Currículo e Processo Formativo- Inovação e Interdisciplinaridade Professora da Secretaria de Estado de Educação do Distrito Federal desde 1997. E-mail: ednna_mara@yahoo.com.br/ ednna.marai@gmail.com Lattes iD: http://lattes.cnpq.br/5391644040342894 Orcid iD https://orcid.org/oooo-oooz-9268-4395.
} 
discourse and the daily life of schools already militarized. The methodology consisted of reviewing dissertations that investigated militarized schools showing the contradictions of what actually happens in these schools and the Ordinances on or/2019 and 09/2019 that consolidated the Shared Management Schools. We are based on Historical-Critical Pedagogy and Critical Theory, with Bourdieu and Althusser. We seek in Weber his reading about the State as the holder of legitimate violence. We note that the State exercises violence against working class students through the school and the military police in the form of educational policies; the contradictions between the militarization discourse and the daily life of schools already militarized reveal the alignment with neoliberal educational policies.

Keywords: Militarization of public schools. Violence. Modern State. State Ideological Apparatus. State Repressive Apparatus.

\section{INTRODUÇÃO}

As políticas implementadas no Brasil após o golpe de 2016 (impeachment), alinhadas às demandas econômicas do neoliberalismo, agravaram a situação do trabalhador brasileiro, entre elas estão o congelamento de investimentos em educação e saúde (PEC 2I4 ou PEC 55), a reforma do Ensino Médio (Lei 13.415/2017), a nova organização curricular (BNCC Resolução CNE/CP no 2/2017), a proposta de "uma escola sem partido" (PL 7.18o/2014), a reforma trabalhista e da previdência (Lei 13.467/2017).

Com a instauração do governo de extrema direita em 2018, este cenário é ampliado, uma das medidas consolidadas é a militarização das escolas públicas, por meio do Decreto $\mathrm{n}^{\circ}$ 10.004/2019 e da Portaria no 2.015/2019. Não há como falar de qualquer fenômeno escolar sem considerar as determinações econômicas, políticas, culturais e históricas em que ele acontece. Portanto, localizamos a escola numa sociedade de contradições, tais como a cultura hegemônica do branco dominante, as relações de classe e poder, as questões étnicas e de gênero, a exploração da classe trabalhadora, a exclusão social, as políticas de precarização do trabalho e do trabalhador. Consideramos ainda o fato de o Brasil ter uma história colonial, escravagista e de golpe militar, com uma jovem (re)democracia em pleno retrocesso. Nesse sentido, nos lembra Libâneo (1987, p. 75):

[...] a contribuição da escola para a democratização está no cumprimento da função que lhe é própria: a transmissão/assimilação ativa do saber elaborado. Assume-se assim, a importância da escolarização para todos e do desenvolvimento do ser humano total, cujo ponto de partida está em colocar à disposição das camadas populares os conteúdos culturais mais representativos do que de melhor se acumulou, historicamente, do saber universal, requisito necessário para tomarem partido no projeto histórico-social de sua emancipação humana. 
São objetivos deste estudo: compreender de que forma o Estado exerce a violência legítima nas escolas públicas militarizadas e revelar as contradições entre o discurso de militarização e o cotidiano das escolas já militarizadas.

A metodologia constituiu de revisão de dissertações de Mestrado que investigaram as escolas militarizadas para mostrar as contradições reais do que de fato acontece nessas escolas e as Portarias Conjuntas $\mathrm{n}^{\circ}$ ol/2019 e $\mathrm{n}^{\circ} 09 / 2019$ que consolidaram o projeto Escolas de Gestão Compartilhada, transformando quatro escolas públicas do Distrito Federal em Colégios da Polícia Militar. Na perspectiva crítica que fundamenta este estudo, as teorias educacionais que darão sustentação ao trabalho são a Pedagogia Histórico-crítica, principalmente com Saviani e Freitas; a Teoria Crítica- Teoria do Sistema de ensino enquanto violência simbólica de Bourdieu e Teoria dos aparelhos ideológicos do Estado (AIE) e aparelhos repressores do Estado (ARE) de Althusser. Para melhor compreensão dos conceitos de violência e Estado, buscamos em Weber a sua leitura sobre o Estado Moderno como detentor da violência legítima.

Para a Pedagogia Histórico-crítica, um projeto educacional expressa interesses, valores e visa a formação de determinados sujeitos (em se tratando da escola pública, a formação da classe trabalhadora), para assumir determinados papeis, de acordo com o pensamento dominante revelado por meio do currículo. "A escola é determinada socialmente; a sociedade em que vivemos, fundamentada no modo de produção capitalista, é dividida em classes com interesses opostos; portanto, a escola sofre a determinação do conflito de interesses que caracteriza a sociedade" (SAVIANI, 20II, p. 25).

Apresentamos como pressupostos deste trabalho:

- O Estado exerce a violência de forma legítima por meio do aparato militar inserido nas instituições públicas de ensino.

- A violência sobre os estudantes da classe trabalhadora se dá pelos aparelhos ideológicos e repressores do Estado representados pela escola e pela polícia militar em forma de políticas educacionais.

- As contradições entre o discurso de militarização e o cotidiano das escolas já militarizadas revelam o alinhamento às políticas educacionais neoliberais.

$\mathrm{O}$ interesse pelo estudo se deu em meio às discussões nas aulas de Teoria Social (Curso de Mestrado da Universidade de Brasília) e pelo fato de a autora realizar pesquisa sobre o currículo das escolas militarizadas do Distrito Federal. No decorrer dessa investigação, ampliou-se o campo de visão da pesquisadora sobre as contradições presentes na sociedade e sobretudo, na educação brasileira, reforçando a necessidade de luta pela superação da realidade que ora se apresenta onde a exploração do trabalhador atingiu o máximo de perversidade e desumanização. Como professora da rede pública de ensino, maior ficou o engajamento na prática educativa, por reforçar a crença na educação como fator de transformação e emancipação humana por meio do conhecimento historicamente produzido pela humanidade que é apropriado pela classe dominante. 
No primeiro tópico apresentamos a escola e sua função social situada em meio às políticas reformadoras, destacando a militarização como uma das ações do que Freitas (2018) chama de reforma empresarial da educação.

\section{Políticas educacionais neoliberais e a militarização das escolas públicas}

A escola que conhecemos é de origem recente, confundindo-se com a própria história da transformação e desenvolvimento do capitalismo. Para compreendermos o papel da escola na sociedade capitalista, segundo Saviani (1999), devemos entender sua concepção filosófica (quem pensou, o que pensou, para quem pensou), a teoria ou pedagogia que corrobora com essa fundamentação e por fim, as práticas pedagógicas que organizam a escola. Chama a atenção para o fato de a escola nessa sociedade marginalizar determinados grupos sociais para manutenção da ordem capitalista. Coloca num primeiro grupo as teorias de educação como instrumento de equalização social, de superação da marginalidade. Num segundo grupo, as teorias que entendem a educação como instrumento de discriminação social e como fator de marginalização. Apresenta uma terceira teoria - Teoria Crítica - que trabalha na superação da marginalização.

O saber que diretamente interessa à educação é aquele que emerge como resultado do processo de aprendizagem, resultado do trabalho educativo, para chegar a esse resultado a educação tem que partir, tem que tomar como referência, como matéria-prima de sua atividade, o saber objetivo produzido historicamente. A escola é o espaço privilegiado de transmissão do conhecimento historicamente produzido (ciência, arte, filosofia) às novas gerações, conhecimento esse que propicia as condições de emancipação humana (SAVIANI, 20II). Em contradição a essa ideia, Santos (2016) vivenciou na escola militarizada que:

Dessa maneira, ao tentar se enquadrar na LDB, o Regimento Interno do CPMG oculta sua verdadeira prática. No fundo, o que está em jogo é outro tipo de gestão escolar e de conduta, a escola se pauta pela centralização do poder e pelo autoritarismo. É hierarquizante, exerce controle, vigilância e punição, parte de uma figura central, o comandante e diretor e, de forma cadente, os demais militares que ocupam outros cargos de chefia (p.56).

Retomando o atual cenário neoliberal, a educação tem resistido às políticas reformadoras que visam o fracasso da escola para legitimar sua entrega à iniciativa privada, chamada por Freitas (2018) de reforma empresarial da educação. Afirma o autor que há uma separação entre os que concebem a educação e os que a praticam, chamando a atenção para a nova corrente neoliberal- conservadora e reacionária- que não se limita a qualquer ação moral para atingir seus objetivos, quais sejam de minimizar a ação do Estado por meio da retirada de direitos e enfraquecendo a democracia, pois estes são elementos fundantes do mercado.

O conceito de sociedade e de educação que o neoliberalismo toma como fundamento coloca os indivíduos em um cenário de "competição" entre eles- algo como uma seleção 
natural na qual as noções de solidariedade e democracia perdem cada vez mais sentido prático. A finalidade educativa da escola é vista como uma "oportunidade" que o aluno tem para "competir" - independentemente das suas condições de vida (FREITAS, 2018).

Em sua dissertação, Bezerra (2016, p. 98) constatou:

\begin{abstract}
A sintonia dessas políticas com os pressupostos neoliberais, que concebem o sucesso a partir do mérito individual, além de justificar a exclusão social como um mal necessário para o desenvolvimento, permite classificá-las como projeto que visa intensificar a exploração dos trabalhadores.
\end{abstract}

A militarização das escolas públicas faz parte do movimento de reforma. Tolerância zero com a disciplina, mais autoritarismo na escola e, portanto, mais segregação; a proposta de eliminar os "tomates podres" antes que estraguem os bons ampliam a ação repressora nas escolas. Para onde vão os "desajustados" não importa- o importante é "livrar-se" deles. "As escolas não militarizadas, obrigadas, por força da lei, a garantir o acesso e a permanência de todos que buscam a educação pública, recebem rótulos de ineficientes por acolher a todos, mesmo aqueles que foram considerados "indesejados" nos colégios geridos pelos militares" (BEZERRA, 2016, p. 95).

A entrega de escolas públicas para serem administradas pela polícia militar, sob o argumento de se "garantir o direito de aprendizagem para todos", revela uma triste contradição se o verbo "garantir" for entendido como "dar oportunidades de aprendizagem para todos" - transferindo para o estudante a responsabilidade de se tornar um "empreendedor de si mesmo" (FREITAS, 2018). E como sempre acontece nestas iniciativas, estudantes que se destacam ganham condecorações, e quem não se adapta é transferido. É o poder do Estado manifestado sob a forma de violência disfarçada de civismo e disciplina, como verificou Castro (2016):

\footnotetext{
Na entrevista que realizei com o Diretor e Capitão Santos, conversávamos sobre o significado dos símbolos militares na escola, quando ele comentou: "Eu sempre falo assim: a diferença de nós militares é que nós somos treinados para dar a vida pela sociedade. Se tiver que morrer, eu morro pela sociedade. O cidadão comum, não. Ele é treinado para roubar. Ele é treinado para ser beneficiado. Ele trabalha em torno de si. Essa é a nossa diferença (p. 93).
}

No tópico seguinte apresentamos a compreensão do Estado Moderno, buscamos em Weber a fundamentação do Estado como detentor legítimo da violência e em Althusser a ideia de aparelhos ideológicos (AIE) e aparelhos repressores (ARE) do Estado para mostrar como é exercida a violência nas escolas públicas.

\title{
2 O Estado como detentor da violência
}

As instituições sociais, econômicas e culturais modernas no ocidente se desenvolveram por meio de um processo geral de racionalização, entendido como o 
resultado da especialização científica e da diferenciação técnica peculiar à civilização ocidental. Para Freund (1975, p. 19):

Consiste na organização da vida, por divisão e coordenação das diversas atividades, com base em um estudo preciso das relações entre os homens, com seus instrumentos e seu meio, com vistas à maior eficácia e rendimento. Tratase, pois, de um puro desenvolvimento prático operado pelo gênio técnico do homem.

A organização da economia capitalista e do Estado Moderno, assim como a própria relação entre ambos, é realizada pelo princípio normativo assentado no direito formal. A organização da economia capitalista molda a empresa capitalista: contabilidade racional, introdução de uma eficiente e formal mão de obra livre, utilização do conhecimento técnico-científico e por decisões de investimento orientadas para o mercado. O núcleo organizativo do Estado Moderno, por sua vez, caracteriza-se, entre outros aspectos, por meio da introdução de um central e contínuo sistema tributário, um central comando militar, pelo monopólio do uso da violência e por uma administração burocrática (MALISKA, 2006).

Para Marx (1993), o Estado não é o representante da sociedade ou do interesse da coletividade, mas sim uma instituição a serviço de um grupo- classe dominante-, contra outros grupos menos favorecidos, é essencialmente classista, representante de uma classe e não da sociedade em sua totalidade. Afirma que não é o Estado o determinante da organização da sociedade, mas sim, a sociedade, em suas relações de classe, que determinam a estrutura do Estado. "[...] o poder político do Estado representativo moderno nada mais é do que um comitê para administrar os negócios comuns de toda a classe burguesa" (p. 96). A função do Estado, segundo ele, é defender os interesses das classes dominantes por meio de seus instrumentos de regulação, a saber o sistema jurídico e o aparato militar e policial.

A lógica acionada é da guerra, onde não cabe a moldura dos controles democráticos e dos limites impostos pelas leis. A narrativa apresentada pelos policiais é de que o inimigo (criminoso/suspeito) está sempre bem armado e enfrenta a polícia com poder de fogo e risco para os policiais (Renato Alves e Fernando Salla, do NEV USP) $)^{2}$.

Weber (1999) por sua vez, conceitua o Estado como uma forma específica de política que não se define pelo consenso e participação popular, mas justamente pelo monopólio da violência, o Estado é a estrutura ou o agrupamento político que reivindica com êxito o monopólio do constrangimento físico legítimo. Tem o poder de coerção sobre os indivíduos e de formular leis para controlar a conduta da sociedade. Nesse sentido, para que

2 Disponível em: https://g1.globo.com/monitor-da-violencia/noticia/2020/09/03/no-de-pessoas-mortas-pelapolicia-cresce-no-brasil-no-1o-semestre-em-plena-pandemia-assassinatos-de-policiais-tambem-sobem.ghtml acesso em 24 out. 2020. 
o Estado exista, os dominados devem obedecer à autoridade declarada pelos detentores. "se só existissem estruturas sociais de que a violência estivesse ausente, o conceito de Estado teria também desaparecido [...]" (WEBER, 1999, 56).

O Estado é uma relação de homens dominando homens, relação mantida por meio da violência legítima (considerada como legítima) num conjunto de regras e hierarquias que protegem o funcionamento estatal; é possível sustentar a estrutura social fazendo a manutenção do poder e controle da população justamente pelo uso legítimo de força e coerção. Portanto o Estado Moderno é um instrumento legítimo de dominação e poder, é fruto do desenvolvimento do capitalismo ocidental já que a complexidade desta nova organização socioeconômica demanda uma administração de cunho racionalista e burocrático (WEBER,1999).

Quanto à dominação, Weber (I999, p. 59) levanta o seguinte questionamento: "de que modo conseguem as forças políticas dominantes afirmar sua autoridade?" Responde ele, "essa indagação diz respeito a todos os tipos de dominação e vale, consequentemente, para todas as formas de dominação política, legalista ou carismática”. A dominação organizada, necessita, por um lado, de um estado-maior administrativo e, por outro lado, necessita dos meios materiais de gestão. No Estado-maior “os funcionários ou outros magistrados, de cuja obediência depende o detentor do poder, são, eles próprios, os proprietários dos instrumentos da gestão, instrumentos esses que podem ser recursos financeiros, edifícios, material de guerra, parque de veículos, cavalos etc”. Os meios materiais, por oposição, privam o estadomaior dos meios de gestão, no mesmo sentido em que, na época atual, o empregado e o proletário são 'privados' dos meios materiais de produção numa empresa capitalista".

É a partir dessa concepção de Estado que situaremos a militarização das escolas públicas, com fundamentação em Althusser- Aparelhos Ideológicos e Repressores do Estado- reforçaremos a ideia do Estado como detentor da violência.

Corroboramos com Lombardi (20II) de que que a escola tem um importante papel na educação dos trabalhadores, possibilitando o domínio das ferramentas teóricas para uma compreensão crítica do mundo, por meio do acesso aos saberes historicamente produzidos pela humanidade, condição elementar para assumir as rédeas do poder político.

\subsection{Aparelhos Ideológicos e Repressores do Estado}

A instituição policial que conhecemos, teve origem na Europa e na América no final do século XIX, em consequência dos temores das classes governantes quanto às ameaças à ordem estabelecida. Polícia, histórica e universalmente, foi criada para controlar a ordem social (LASSERRE, 2002). Foi criada para confrontar as classes perigosas, para controlar protestos das classes populares e preservar a estrutura social, e não apenas para combater o crime, ou promover as guerras contemporâneas contra o crime (PINHEIRO, 1998, p.I8I).

$\mathrm{Na}$ Idade Média a Polícia compreendia a boa ordem da sociedade civil, da competência das autoridades políticas do Estado, em contraposição à boa ordem moral, do cuidado exclusivo da autoridade religiosa. Na Idade Moderna, seu sentido compreendeu ainda toda a 
atividade da administração pública, um ordenamento em que toda a função administrativa era indicada com o termo de Polícia. Este termo voltou a ter um significado mais restrito, quando no início do século XIX passou a identificar-se com a atividade tendente a assegurar a defesa da comunidade dos perigos internos. Tais perigos estavam representados nas ações e situações contrárias à ordem e à segurança pública. Na sua evolução, a Polícia, já na condição de aparelho do Estado Nacional, assumiu a tarefa de proteger a propriedade e exercer controle sobre o comportamento público, o que na sociedade tradicional ficava a cargo de particulares. Hoje existe, o conceito de Polícia mais generalizado e universalmente traduzido, segundo Bobbio (200o, p.944) como:

Função do Estado que se concretiza numa instituição de administração positiva e visa pôr em ação as limitações que a lei impõe à liberdade dos indivíduos e dos grupos para salvaguardar a manutenção da ordem pública, em suas várias manifestações: da segurança das pessoas à segurança da propriedade, da tranqüilidade dos agregados humanos à prote- ção de qualquer outro bem tutelado com disposições penais.

Costa (2005) diz que historicamente, a atuação da Polícia no Brasil como instituição, embora mereça ressalvas, principalmente nos períodos ditatoriais, é reconhecida como importante e necessária. Nos governos de exceção, o caráter repressivo da Polícia baseou-se nos pressupostos da segurança nacional e, também, nos requisitos da normalidade econômica. Isso ocorreu por meio de um regime de força, de operação e combate, de desvio do emprego dos órgãos policiais em missão de polícia política e de operação de defesa interna. Tudo em detrimento das atividades primárias de proteção ao cidadão e da manutenção da ordem pública. "Isso demonstra o preparo e a consciência nas ações desenvolvidas por estes profissionais, que só reagem quando há desobediência de ordem do poder de polícia, ou quando os suspeitos atiram contra um policial armado" (Secretaria de Segurança do Estado do Mato Grosso3).

Passado o período de governo militar, a Constituição Federal (BRASIL, I988), no Artigo 144, parágrafo $5^{\circ}$ decreta que: "Às polícias militares cabem a polícia ostensiva e a preservação da ordem pública." Em contradição ao que está expresso na constituição federal, dados do Monitor da Violência ${ }^{4}$ apontam que o Brasil teve ao menos 3.148 pessoas mortas por

\footnotetext{
3 Disponível em: https://gi.globo.com/monitor-da-violencia/noticia/2020/o9/o3/no-de-pessoas-mortas-pelapolicia-cresce-no-brasil-no-ı-semestre-em-plena-pandemia-assassinatos-de-policiais-tambem-sobem.ghtml acesso em 24 out. 2020.

4 Monitor da Violência, uma parceria entre o GI, o Núcleo de Estudos da Violência da USP e o Fórum Brasileiro de Segurança Pública, utiliza a metodologia acadêmico-científica do NEV e do FBSP; os dados, inéditos, fazem parte de um levantamento com base nos dados oficiais de 25 estados e do Distrito Federal, apenas Goiás se recusa a passar os dados. Foram solicitados os casos de "confrontos com civis ou lesões não naturais com intencionalidade" envolvendo policiais na ativa. Os pedidos foram feitos para as secretarias da Segurança Pública dos estados por meio da Lei de Acesso à Informação e das assessorias de imprensa. Disponível em: https://gi.globo.com/monitor-da-violencia/noticia/2020/o9/o3/no-de-pessoas-mortas-pelapolicia-cresce-no-brasil-no-ı-semestre-em-plena-pandemia-assassinatos-de-policiais-tambem-sobem.ghtml acesso em 24 out. 2020.
} 
policiais no primeiro semestre de 2020- um aumento de 7\% em relação ao mesmo período de 2019, quando foram registradas 2.934 vítimas (sem contar Goiás em ambos os anos); a taxa de mortes pela polícia ficou em I, 5 a cada Ioo mil habitantes; o Rio de Janeiro é o estado com mais pessoas mortas no primeiro semestre: 775; o Amapá é o estado com a maior taxa de letalidade policial: 8,I por roo mil habitantes.

Para Althusser (1980), o Estado se constitui por instituições da sociedade civil concebidos como aparelhos ideológicos e repressores, sendo estes últimos representados pela polícia, as forças armadas, os tribunais e outros que atuam por meio da violência. “[...] sobretudo, o aparelho de Estado assegura pela repressão (da mais brutal força física às simples ordens e interditos administrativos, à censura aberta ou tácita, etc.), as condições políticas do exercício dos aparelhos ideológicos de Estado" (p. 56).

Há um discurso bastante generalizado entre as polícias de que as operações são inevitáveis para controle do crime. Enquanto isso, a gente observa que as operações caíram, as mortes em geral caíram e os indicadores criminais não subiram. A gente começa a perceber que a preservação da vida não se opõe ao controle do crimes.

As relações de dominação expressas na diferença de tratamento entre as classes ${ }^{6}$ sociais revela as atuações violentas e preconceituosas às classes menos favorecidas:

O adolescente João Pedro Mattos Pinto, de 14 anos que foi morto durante uma operação conjunta das polícias Federal e Civil no Complexo do Salgueiro, em São Gonçalo- RJ, em 18 de maio de 2020. De acordo com relatos de parentes, a polícia invadiu a casa em que João estava. Um dos presentes gritou que só havia crianças na residência, deitadas no chão e com as mãos para cima. "Os policiais saíram atirando", escreveu um primo numa rede social. "A polícia chegou lá de uma maneira cruel, atirando, jogando granada, sem perguntar quem era. Se eles conhecessem a índole do meu filho, quem era meu filho, não fariam isso", diz Neilton Pinto, pai de João Pedro. "Um jovem de 14 anos, um jovem com um futuro brilhante pela frente, que já sabia o que queria do seu futuro. Mas, infelizmente a polícia interrompeu o sonho do meu filho." 7

\footnotetext{
${ }_{5}$ Daniel Hirata, professor de Sociologia da Universidade Federal Fluminense (UFF) e coordenador do Grupo de Estudos dos Novos Ilegalismos-Geni. Disponível em: https://gi.globo.com/monitor-daviolencia/noticia/2020/o9/03/no-de-pessoas-mortas-pela-policia-cresce-no-brasil-no-Io-semestre-em-plenapandemia-assassinatos-de-policiais-tambem-sobem.ghtml acesso em 24 out. 2020.

${ }^{6}$ A concentração do capital gera efeitos poderosos, como a exclusão, estigmatização e tentativa de destruição das classes pobres, especialmente da juventude, por meio da opressão e criminalização. (COIMBRA; NASCIMENTO, 2003. In SOUZA, C.; PAIVA, I. L. de. Faces da juventude brasileira: entre o ideal e o real. Estudos de Psicologia, Universidade Federal do Rio Grande do Norte, v. 17, n. 3, p. 353-36o, set./dez. 2012). 7 Disponível em: https://gi.globo.com/monitor-da-violencia/noticia/2020/o9/o3/no-de-pessoas-mortas-pelapolicia-cresce-no-brasil-no-ı-semestre-em-plena-pandemia-assassinatos-de-policiais-tambem-sobem.ghtml acesso em 24 out. 2020.
} 
A atuação dos militares, sobretudo da polícia, nas escolas públicas mostra como o Estado se utiliza dos mecanismos repressivos, disfarçados sob o discurso de que o projeto visa aumentar as taxas de aprovação e maior inserção dos estudantes no mundo do trabalho; reduzir as taxas de reprovação, abandono e evasão escolar; alcançar e superar as metas estabelecidas para o Índice de Desenvolvimento da Educação Básica- Ideb; facilitar a construção de valores cívicos e patrióticos; aumentar a disciplina e o respeito hierárquico; formar os discentes para o exercício da plena cidadania; obter avanços nos parâmetros de segurança pública cidadã; reduzir o índice de criminalidade no âmbito escolar (BRASÍLIA, 2019a). A contradição a essa ideia é revelada por Belle (20II) em uma escola militarizada:

\begin{abstract}
Essa forma de lidar com a condução das atividades na escola pode provocar impacto negativo no comportamento dos estudantes. De um lado age um grupo de estudantes, executando funções que visam manter a ordem, e investidos de poder para denunciar aqueles que infringem os regulamentos e orientações superiores; e de outro, aquele que, considerado incapaz de exercer o comando, sente-se vigiado e insatisfeito. Verifica-se que nessa circunstância não existe conflito na relação, mas aquele que vigia e denuncia, determina atividades e os outros, que obedecem. Mais uma vez, os direitos e deveres declarados, os princípios considerados basilares à conquista da cidadania, contraditoriamente, pelo menos no Colégio Beta, não são aplicados no dia a dia (p. 7r).
\end{abstract}

A força policial inserida nas escolas públicas onde estudam os filhos da classe trabalhadora, reforça as desigualdades e obriga, por meio da disciplina e punição, os estudantes (futuros trabalhadores) a obedecer e acatar as regras do sistema neoliberal sem contestação, de forma disciplinada e naturalizada como se não houvesse outra realidade possível. Para Bourdieu (2007) o Estado, representado pelo sistema escolar, ao não propiciar acesso democrático à cultura específica para todos, reforça as distinções de capital cultural dos estudantes. Castro (2016, p. 49), relata em sua dissertação:

O impacto daquela cena em mim, entretanto, não foi gerado tanto pela atenção e silêncio que partiram da turma, mas pela prontidão, pela postura e movimento corporais e pela sincronia entre aquelas crianças. Eu me perguntava qual era o significado daquele procedimento, se os professores se incomodavam ou aprovavam e como foi o processo de os estudantes aprenderem aqueles movimentos e comandos.

Para Althusser (1970), a escola é um dos principais aparelhos ideológicos do Estado, ela ensina diferentes padrões de comportamento, dependendo da classe que os estudantes pertençam e do trabalho que realizarão. A ideologia empregada pelos aparelhos ideológicos do Estado (AIE) é a ideologia das elites dominantes- burguesa capitalista. Essas elites controlam os ARE e os AIE, reproduzindo o poder repressivo e ideológico para manter a propriedade privada e a exploração do trabalhador. "A insegurança quanto à forma de proceder é uma constante por parte do aluno, que, diante de uma autoridade militar, em 
qualquer local e horário, tem de estar atento em relação à continência e aos gestos e atitudes da mencionada autoridade" (BELLE, 20II, p.17o)

A polícia nas escolas públicas representa o Estado por meio do aparelho repressor que garante pela força física, as condições apropriadas para a reprodução das relações de produção e exploração. "[...] o papel do aparelho repressivo de Estado consiste, essencialmente, enquanto aparelho repressivo, em assegurar pela força (física ou não) as condições políticas da reprodução das relações de produção que são em última análise relações de exploração (ALTHUSSER, 198o, p. 56).

No próximo tópico pretendemos desvelar o contexto em que as representações simbólicas são construídas e legitimadas- a violência atribuída aos jovens e a violência na escola-, revelando como o Estado se vale do imaginário comum para exercer o uso da força, coesão, repressão, uma vez que essas têm sido justificativas para a militarização das escolas públicas.

\section{A construção social da juventude violenta e perigosa e a violência do Estado contra a escola e os estudantes da classe trabalhadora}

A violência nas escolas tem sido repercutida em diversos setores da sociedade, reforçando o imaginário social de que os jovens neste início de século são violentos e perigosos e que a escola é o local em que a violência se manifesta, desconsiderando-se que a adolescência e a juventude são construções históricas, assim como a atribuição da violência e periculosidade. Lembramos que a história não é um processo que se passa por sobre os homens, e sim uma construção dos próprios homens que, cotidianamente fazem a história num processo cujo fundamento está na produção material da vida social. Não se trata de um processo construído idealmente, mas materialmente (HÚNGARO, 2014).

À medida que a sociedade se transforma, a violência ganha novas representações, se refere às noções de constrangimento e de uso da superioridade física sobre o outro, a conflitos de autoridade, a lutas pelo poder e a vontade de domínio, de posse e de aniquilamento do outro ou de seus bens, seja sob a utilização da força física, psíquica, moral, ou como forma de ameaça ou atemorização (MINAYO, 2006).

A noção de infância surge no século XVII acompanhada das transformações que se davam na transição para a sociedade moderna. A criança, por muito tempo, não foi vista como um ser em desenvolvimento, com características e necessidades próprias, e sim "homens de tamanho reduzido" (ARIÈS, I98I, p. I8).

A adolescência tem origem na modernidade, é um fenômeno histórico com determinação econômica que se deu em meio à consolidação do modo de produção capitalista. Nas palavras de Marx, as fábricas recrutavam seus contingentes à força, revelando a necessidade do roubo e escravização das crianças para transformar a exploração manufatureira em exploração industrial e estabelecer a correta proporção entre capital e força de trabalho" (2006). 
As ideias escolanovistas chegam ao Brasil no início do século XX, afirmando que a criança é um ser ativo e integrante da sociedade, com especificidades próprias do seu processo de desenvolvimento como ser humano, passando a ser entendida como uma fase que exige cuidados e acompanhamento (ARANHA, 2006). Entretanto, às crianças e jovens pobres, por não constituírem a ampla reserva de mão-de-obra, outras produções subjetivas e rótulos são adicionados, entre eles, a violência, a periculosidade e a criminalidade ${ }^{8}$.

No contexto capitalista, a miséria é percebida e explicada como fruto da ociosidade, da preguiça e dos vícios próprios dos pobres, tornando natural as medidas contra a pobreza, percebida e tratada como possuidora de uma moral duvidosa transmitida hereditariamente (MARX, 2006). A ideia de juventude perigosa ao longo do século XX pouco mudou, no século XXI o que se vê são os jovens da periferia destituídos de seus direitos fundamentais, rotulados de marginais ou desviados. "A pessoa a quem se aplica o rótulo do desvio é geralmente considerada como moralmente inferior, e sua "condição" ou comportamento é frequentemente interpretado como evidência de sua "culpabilidade moral". (APPLE, 2006, p. 185$)$.

A manutenção do status quo no cenário neoliberal ativa os mecanismos de adequação e controle das contradições, entre o que é prometido e o que é de fato produzido na vida da maioria das pessoas, dificultando a compreensão do real papel desempenhado pela polícia ${ }^{9}$ nas escolas em que estudam os filhos da classe trabalhadora. As restrições impostas pelo capital em seus discursos e ações dissimulados, desinteressados, entendidos como naturais, excluem, estigmatizam e tentam destruir a pobreza ${ }^{10}$, sobretudo sua infância e juventude. "A aplicação da hierarquia e disciplina melhora a qualidade de ensino dos estudantes"; "os

\footnotetext{
${ }^{8}$ A concentração do capital gera efeitos poderosos, como a exclusão, estigmatização e tentativa de destruição das classes pobres, especialmente da juventude, por meio da opressão e criminalização. (COIMBRA; NASCIMENTO, 2003. In SOUZA, C.; PAIVA, I. L. de. Faces da juventude brasileira: entre o ideal e o real. Estudos de Psicologia, Universidade Federal do Rio Grande do Norte, v. 17, n. 3, p. 353-360, set./dez. 2012).

${ }^{9}$ Diante da farsa da igualdade de direitos naturais, e da necessidade da burguesia em manter o estado de coisas sem comprometer seu discurso, alguns instrumentos foram criados para a manutenção da ordem a partir dos interesses da classe dominante. A função primordial exercida pelas forças de segurança ostensiva, materializada pelas polícias militares, por exemplo, é a de exercer um processo de coerção travestindo-se com uma aura de reguladora da ordem e do bom funcionamento social, partindo do pressuposto de que, se todas as pessoas são iguais em direitos, aquelas que fogem ao ordenamento legal devem ser reprimidas por comprometer o bem-estar e o bom funcionamento dessa sociedade (VARLINDO NASCIMENTO, https://www.pagina13.org.br/ocarrasco-o-capitao-do-mato-e-a-policia-militar/ Acesso em 12/08/2020).

${ }^{10}$ Sob a forte influência do movimento higienista, na década de 1920, se construiu a ideia dos bandidos de nascença e do mito no qual os jovens pobres estão diretamente associados à periculosidade e, portanto, devem ser descartados. Assim, os jovens pobres, que sobreviviam ao extermínio, geravam a parcela excluída por excelência, pois sequer chegavam ao mercado de trabalho formal. Caracterizavam um "perigo social" a ser controlado, justificando e fortalecendo as políticas repressoras voltadas a essa população. Essa vinculação da juventude com a desordem social é uma concepção que contribui fortemente até os dias atuais para reforçar a relação entre vadiagem/ ociosidade/ pobreza; entre pobreza e periculosidade/ violência/ criminalidade (COIMBRA; NASCIMENTO, 2003 apud SOUZA; PAIVA, 2012, p. 355).
} 
CPM ajudam a preparar cidadãos respeitosos e obedientes"; "as escolas geridas por policiais são mais organizadas"; "é um dos sistemas públicos mais eficientes da educação brasileira" (SANTOS, 2016, p. 29).

\section{I A violência do Estado contra a escola e os estudantes da classe trabalhadora}

O projeto Escola de Gestão Compartilhada foi implementado no Distrito Federal por meio da Portaria Conjunta no or/2019 (BRASÍLIA, 2019a), transformando, no ano de 2019, quatro unidades de ensino da rede pública em Colégios da Polícia Militar do Distrito Federal (CPMDF). A Portaria Conjunta no 09/2019 (BRASÍlLIA, 2019b), reforça a Portaria Conjunta $\mathrm{n}^{\circ}$ or/2019, fortalece a parceria entre a Secretaria de Estado de Educação do Distrito Federal - SEEDF e a Secretaria de Estado de Segurança Pública do Distrito Federal - SSP/DF e altera o nome das escolas para Colégios Cívico-Militares do Distrito Federal.

A Escola de Gestão Compartilhada, ao inserir os militares nas instituições públicas de ensino, desconsidera a Constituição Federal que delega a estes a preservação da ordem pública. "Às polícias militares cabem a polícia ostensiva e a preservação da ordem pública; aos corpos de bombeiros militares, além das atribuições definidas em lei, incu mbe a execução de atividades de defesa civil" (BRASIL, 1988, artigo I44).

\section{Quadro I- Escolas militarizadas do Distrito Federal- 2020}

\begin{tabular}{|c|c|c|}
\hline $\mathrm{N}^{\circ}$ & & Escolas de Gestão Compartilhada SEE/ SSP-DF \\
\hline OI & PM-DF & Centro Educacional o3 de Sobradinho \\
\hline 02 & PM-DF & Centro Educacional 308 do Recanto das Emas \\
\hline 03 & PM-DF & Centro Educacional or da Estrutural \\
\hline 04 & PM-DF & Centro Educacional o7 da Ceilândia \\
\hline 05 & CBM-DF & CEF i9 de Taguatinga \\
\hline 06 & CBM-DF & CEF i do Núcleo Bandeirante \\
\hline 07 & CBM-DF & CEF 407 de Samambaia \\
\hline o8 & PMDF & CED Condomínio Estância III de Planaltina \\
\hline 09 & PM-DF & CED i do Itapoã \\
\hline \multicolumn{3}{|r|}{ Escolas em processo de implementação } \\
\hline Io & PM-DF & CEF i do Riacho Fundo II \\
\hline \multicolumn{3}{|c|}{ Total: ro escolas } \\
\hline \multicolumn{3}{|c|}{ Escolas Cívico-Militares- projeto federal em processo de implementação- MEC } \\
\hline or & Forças Armadas & CED 4 I6 de Santa Maria \\
\hline 02 & Forças Armadas & CEF 5 do Gama \\
\hline \multicolumn{3}{|c|}{ Total: 2 escolas } \\
\hline \multicolumn{3}{|c|}{ Total geral: 12 escolas } \\
\hline
\end{tabular}


Em defesa da democratização da escola e do ensino, o Projeto de Decreto Legislativo (PDL) no oo8/2019 (DISTRITO FEDERAL, 2019) tentou sustar a Portaria Conjunta no oI/2org (BRASÍLIA, 2019a). Considerou a portaria inválida pela ausência de manifestação prévia do Conselho Distrital de Educação; destacou a lacuna normativa de gestão com a Polícia Militar nas unidades escolares como afronta direta à gestão democrática, revelando que não há legitimidade social, lembra que o poder regulamentar deve obedecer os limites legais das competências do Poder Executivo, em consonância com o princípio da legalidade postulado no artigo 19 da Lei Orgânica do Distrito Federal- LODF (BRASÍLIA, 1993). A portaria afronta diversos documentos legais, não encontra legitimidade social para sua implementação e, por ter vulnerado os limites legais impostos para sua edição, é inválida e ineficaz, por isso deve ter os seus efeitos sustados, entretanto, o projeto de Decreto Legislativo não conseguiu os votos necessários para aprovação.

\footnotetext{
O poder simbólico como poder de construir o dado pela enunciação, de fazer ver e fazer crer, de confirmar ou de transformar a visão do mundo e, desse modo, a ação sobre o mundo [...] O que faz o poder das palavras e das palavras de ordem, poder de manter a ordem ou de a subverter, é a crença na legitimidade das palavras e daquele que as pronuncia, crença cuja produção não é da competência das palavras (BOURDIEU, 2007, p. 14-15)
}

A Nota Técnica no ool/2019 (Ministério Público do Distrito Federal e TerritóriosPromotoria de Justiça de Defesa da Educação- PROEDUC), posicionou-se a favor da legalidade da Portaria Conjunta no or/2019 (BRASÍLIA, 2019a). Lembramos que a nota não leva em conta as atribuições da segurança pública previstas no artigo 144 da Constituição Federal (BRASIL, 1988) e legitima a inserção do aparato militar no disciplinamento dos estudantes. Compreendemos com isso o que diz Bourdieu (2007), a análise aprofundada no âmbito escolar e suas relações sociais, possibilita desvelar sua função ideológica, política e legitimadora de uma ordem arbitrária em que se funda o sistema de dominação vigente nestas instituições.

O sistema educacional consegue reproduzir por meio de uma violência simbólica as relações de dominação, ou seja, a estrutura de classes, reproduzindo de maneira diferenciada a ideologia da classe dominante. A consolidação da violência simbólica permite que a escola não exerça necessariamente a violência física, mas sim a violência mediante forças simbólicas, pela doutrinação e dominação, que força as pessoas a pensarem e a agirem de tal forma que não percebem que legitimam com isso a ordem vigente (BOURDIEU, 2007).

De acordo com a Portaria no 09/2019 (BRASÍLIA, 2019b) são objetivos das Escolas de Gestão Compartilhada: aumentar as taxas de aprovação dos estudantes, assim como no acesso às Instituições de Ensino Superior; proporcionar maior inserção desses estudantes no mundo do trabalho; reduzir as taxas de reprovação e abandono escolar; aumentar a disciplina e o respeito hierárquico; reduzir o índice de criminalidade no âmbito escolar, bem como na região onde a escola esteja situada. No entanto, os dados do Realtório de Gestão-2019- PMDF revela profunda intolerância no tratamento dos estudantes, pois no curto período de janeiro 
a outubro de 2019 foram milhares de punições, mostrando a violência exercida sobre os alunos pelo aparelho repressor. O quadro a seguir apresenta esses dados.

\section{Quadro 2- Atendimentos realizados pelos militares (janeiro a outubro- 2019)}

\begin{tabular}{|c|c|c|c|c|c|c|}
\hline Quesito & $\begin{array}{c}\text { Ced } 3 \\
\text { Sobradinho }\end{array}$ & $\begin{array}{c}\text { Ced } 308 \\
\text { Recanto } \\
\text { das Emas }\end{array}$ & $\begin{array}{l}\text { Ced I } \\
\text { Itapoã }\end{array}$ & $\begin{array}{c}\text { Ced I } \\
\text { Estrutural }\end{array}$ & $\begin{array}{c}\text { Ced } 7 \\
\text { Ceilândia } \\
\end{array}$ & Total \\
\hline Total de alunos atendidos & I.7II & 900 & 1.383 & I.II2 & I.889 & 6.995 \\
\hline $\begin{array}{l}\text { Palestras } \quad \mathrm{p} / \text { comunidade } \\
\text { escolar }\end{array}$ & 77 & 90 & 49 & 5 & 4 & 225 \\
\hline $\begin{array}{l}\text { Atendimento } \\
\text { pais/responsáveis }\end{array}$ & 2.771 & 354 & 95 & 551 & 346 & 4.117 \\
\hline Ocorrências policiais diversas & 8 & 12 & 3 & 5 & 6 & 34 \\
\hline Chamados SAMU e CBMDF & 15 & & & & II & 26 \\
\hline Operações varredura & 18 & & & & 26 & 44 \\
\hline Suspensões & 249 & & & & 384 & 633 \\
\hline Advertências disciplinares & 7875 & 4642 & 6II & 3453 & 5.521 & 22.102 \\
\hline Termos adequação de conduta & & & & 58 & & 58 \\
\hline Visitas extracurriculares & & & & 14 & & 14 \\
\hline
\end{tabular}

Fonte: http://www.pmdf.df.gov.br/index.php/institucionais/24662-20o-dias-de-comando-da-pmdf-mostraum-trabalho-energico-e-com-excelentes-resultados

Verificamos que nas escolas com maior número de ocorrências- suspensão e advertências- não foram realizadas visitas extracurriculares- saída da escola, por exemplo. Em sua Dissertação de Mestrado, Ribeiro (2009, p. 85) afirma que

[...] a própria vigilância exacerbada nos colégios, já são aspectos de diferenciação, seja no comportamento, de professores e alunos, isto porque, além dos militares que fazem rondas nos corredores, as câmeras de segurança dispostas nas salas, e em ambientes externos, já moldam e controlam a conduta da comunidade escolar.

O Regulamento Disciplinar do Colégios Cívico-militares (BRASÍLIA, 2019c), de caráter militar, assegura que as faltas disciplinares são quaisquer violações dos preceitos de ética, dos deveres e obrigações escolares, das regras de convivência social e dos padrões de comportamento estabelecido aos alunos, em função do sistema de ensino peculiar aos Colégios Cívico-Militares do Distrito Federal. O texto do regimento explicita as penalidades como de caráter educativo que visam a preservação da disciplina escolar, da moral e dos bons costumes, elementos básicos indispensáveis à formação integral do aluno e ao pleno exercício da cidadania. Esta é outra contradição revelada no cotidiano, como verificado por Bezerra (2016): 
O Regimento Interno dos CPMGs basicamente reproduz as concepções do Regulamento Disciplinar da Polícia Militar de Goiás (RDPM-GO). Os gestores dos colégios militares se limitaram a apresentar uma versão adaptada do regimento militar às instituições de ensino. Desse modo, os CPMGs, embora se constituam como escolas públicas de educação básica, são regidos por princípios operacionais militares, cujas prerrogativas são usadas para submeter crianças e adolescentes, que não são militares e tampouco escolheram ingressar na carreira militar, à disciplina militar, isso porque parte do contingente que ingressa nos colégios militares sequer possui idade para fazer tal escolha (p.84).

O regulamento disciplinar traz em suas diretrizes as ações e comportamentos consideradas faltas passíveis de punição de cunho disciplinar/militar e não pedagógico, essa é a forma de exercer a violência sobre os estudantes de forma velada, anunciada como bom comportamento. Trouxemos como exemplos: faltas disciplinares de natureza leve: relacionadas à ação ou omissão do aluno, observada no ambiente escolar, se refere à sua imagem e maneira de se portar ou agir, desde que não interfiram na imagem coletiva, ordem interna, externa ou no andamento da rotina escolar. Faltas disciplinares de natureza média: relacionadas à ação ou omissão do aluno que interferem na ordem interna, rotina escolar, convivência coletiva, deveres obrigações ou à prática de reiteradas faltas disciplinares classificadas como de natureza leves. Faltas disciplinares de natureza de grave: relacionadas à ação ou omissão do aluno que interferem na ordem social, na ordem interna, externa ou que configurem: ato infracional, crime ou contravenção para os alunos com maioridade civil e incompatibilidade com os padrões de disciplina dos Colégios Cívico-Militares do Distrito Federal. Como medidas disciplinares o regimento traz: advertência oral; advertência escrita; suspensão de sala de aula; ações educativas; transferência educativa, poderá ser aplicado ao aluno juntamente com as medidas disciplinares o Estudo Orientado de Caráter Educativo. Bezerra (2016, p. 4I), constatou que

\begin{abstract}
$\mathrm{Na}$ gestão da PM, os colégios têm uma rigidez maior que os outros e por isso há pouca tolerância com a indisciplina. Nesse sentido, alunos que não se adequam às condutas esperadas ou reprovam uma vez são transferidos para outras escolas públicas. Não há tentativa de recuperação. Os secundaristas apontam outra problemática: como a PM, considerada por eles como preconceituosa, racista e historicamente assassina da classe trabalhadora, pode influenciá-los com seus métodos pedagógicos e em sua maneira de ensinar? "A militarização estaria além da repressão ideológica, impondo por meio da disciplina militar a ideia de manter a ordem social como está dada" (RECC-GO, 2015).
\end{abstract}

Não podemos esquecer que o ensino médio (o projeto é voltado para o Ensino Fundamental- $6^{\circ}$ ao $9^{\circ}$ ano e Ensino Médio) é constituído predominantemente por adolescentes e jovens. A BNCC (BRASIL, 2017) em referência às Diretrizes Curriculares Nacionais para o Ensino Médio (DCNEM/2oII), recomenda explicitamente a não caracterização dos estudantes desta etapa como um grupo homogêneo, nem conceber a "juventude" como mero rito de passagem da infância à maturidade. Contraditoriamente, o 


\title{
open 2 access
}

projeto caracteriza esses mesmos jovens e adolescentes como violentos e perigosos, atribuindo a eles a violência escolar.

Ao impor a autoridade militar a partir da ideia de que os alunos são violentos e por isso precisam ser disciplinados para aprender, o projeto revela que a fundamentação do Currículo em Movimento (Pedagogia Histórico-crítica e Psicologia Cultural) não se materializa na prática, uma vez que o regime disciplinar militar praticado aos alunos e também aos professores mostra a contradição entre a perspectiva teórica e o modelo de educação militar. "Toda ação pedagógica é objetivamente uma violência simbólica enquanto imposição, por um poder arbitrário, de um arbitrário cultural” (BOURDIEU \& PASSERON, 2013, p.26). Bezerra (2016), presenciou na escola que

\begin{abstract}
A gestão do CPMG é centralizadora e não democrática. A estrutura das unidades escolares é fundamentada na hierarquia e na subordinação, assim como funciona na corporação da PM. Cada hierarquia tem sua função e competência e deve estar subordinada às patentes mais altas. Nessas escolas, os policiais ocupam os cargos mais altos e lhes é atribuída a função de administrar e coordenar majoritariamente as atividades, enquanto compete aos profissionais da educação obedecer às ordens e exercer suas funções de ensinar (p.54).
\end{abstract}

Concordando com Althusser (1980), a escola favorece a formação social capitalista ao sujeitar os indivíduos à ideologia dominante além de garantir a reprodução da submissão às regras da ordem estabelecida dentro desse regime de exploração e repressão. A presença do aparelho repressor na escola revela a violência exercida aos estudantes da classe trabalhadora por meio de modelos que asseguram a sujeição à ideologia dominante, às regras de obediência, hierarquia e disciplina que desvalorizam o conhecimento e a cultura dessa classe. Assim, a violência é gerada na produção contínua de valores, crenças e comportamentos, levando o indivíduo a se posicionar na sociedade de acordo com critérios e padrões do discurso dominante, consolidando, conformando e legitimando os padrões sociais que não são os seus.

\footnotetext{
Vê-se, pois, que o reforçamento da violência material se dá pela sua conversão ao plano simbólico onde se produz e reproduz o reconhecimento da dominação e de sua legitimidade pelo desconhecimento (dissimulação) de seu caráter de violência explícita. Assim, à violência material (dominação econômica) exercida pelos grupos ou classes dominantes sobre os grupos ou classes dominados corresponde a violência simbólica (dominação cultural) (SAVIANI, I994, p. 29-30).
}

Entre os princípios e valores fundantes dos colégios cívico-militares do Distrito Federal estão a hierarquia e a disciplina; o patriotismo e a cidadania; o civismo; a probidade e a ética; a meritocracia; a excelência no ensino; a inovação e a criatividade; a camaradagem e a urbanidade; a coparticipação da comunidade escolar e das Corporações; a responsabilidade social; a lealdade e amizade. Freitas (2018), lembra que esses princípios e valores que adentram as instituições públicas de regime democrático, revelam o alinhamento 
às políticas neoliberais fortemente implementadas pelos governos federal e distrital que colocaram em ação a militarização das escolas públicas.

\section{${ }_{4}$ Considerações Finais}

Em uma realidade de desigualdade social, um dos aspectos fundamentais da violência, compreender a educação, a segurança pública e o papel que cabe à Polícia constituem um desafio para qualquer estudo. Foram objetivos deste trabalho compreender de que forma o Estado exerce a violência legítima nas escolas públicas militarizadas e revelar as contradições entre o discurso de militarização e o cotidiano das escolas já militarizadas.

As portarias que consolidaram o projeto Escolas de Gestão Compartilhada no Distrito Federal (Portaria Conjunta $n^{\circ}$ or/2019 e Portaria Conjunta $n^{\circ} 09 / 2019$ ) se revelaram neste estudo como instrumentos do Estado para exercer a violência sobre os estudantes da classe trabalhadora. As políticas educacionais colocadas em prática pelos governos federal e distrital, de caráter amplamente neoliberal, visam adequar os jovens estudantes às demandas mercadológicas que exigem o indivíduo flexível, adaptável e resiliente frente às perversidades imputadas à classe trabalhadora por meio da precarização das condições materiais de existência.

As contradições entre o discurso de militarização e o cotidiano das escolas já militarizadas revelam que o Estado exerce a violência de forma legítima por meio do aparato militar inserido nas instituições públicas de ensino; a violência sobre os estudantes da classe trabalhadora se dá pelos aparelhos ideológicos e repressores do Estado representados pela escola e pela polícia militar em forma de políticas educacionais.

\section{Referências Bibliográficas}

ALTHUSSER, Louis. Ideologia e aparelhos ideológicos de estado. Lisboa: Presença, I97o. . Ideologia e aparelhos ideológicos de estado. 3. Lisboa: Presença, I980.

APPLE, Michael, W. Ideologia e Currículo. 3. São Paulo: Artmed: 2006.

ARANHA, Maria Lucia de Arruda. História da Educação e da Pedagogia. 3. São Paulo: Moderna, 2006.

ARIÈS, Philippe. História social da criança e da família. 2. ed. Rio de Janeiro: LTC Editora, I981.

BELLE, Helena Beatriz de Moura. Escola de Civismo e Cidadania: Ethos do Colégio Beta da Polícia Militar de Goiás. [manuscrito]: Belle, Helena Beatriz de Moura. Orientadora Profa. Dra. Iria Brzezinski. Goiânia- GO, 2orr. 
BEZERRA, Nilson Pereira. Pacto pela educação: o cumprimento da agenda neoliberal em goiás e a militarização das escolas públicas. [manuscrito]: Bezerra, Nilson Pereira. Orientadora Profa. Dra. Veralúcia Pinheiro. Anápolis- GO, 2017.

BOBBIO, Norberto. Dicionário de política.5. Brasília: Editora da Universidade de Brasília: São Paulo: Imprensa Oficial do Estado, 2000.

BOURDIEU, Pierre. Razões práticas: sobre a teoria da ação. Io. Rio de Janeiro: Bertrand Brasil, 2007.

BOURDIEU, Pierre; PASSERON, Lean-Claude. A reprodução: elementos para uma teoria do sistema de ensino. Tradução de Reynaldo Bairão. 6a Edição. Petrópolis, Rio de Janeiro: Vozes, 2013.

BRASIL. Constituição (1988). Constituição da República Federativa do Brasil. Brasília, DF: Senado Federal: Centro Gráfico, 1988.

. Resolução CNE/CP n ${ }^{\circ}$ 2, de 22 de dezembro de 2017. Institui e orienta a implantação da Base Nacional Comum Curricular, a ser respeitada obrigatoriamente ao longo das etapas e respectivas modalidades no âmbito da Educação Básica. Brasil: Ministério da Educação; Conselho Nacional de Educação; Conselho Pleno, 2017.

. Base nacional comum curricular: ensino médio. Brasília: MEC/Secretaria de Educação Básica, 2018.

Decreto $\mathrm{n}^{\mathrm{o}}$ 10.004, de 5 de setembro de 2019a. Institui o Programa Nacional das Escolas Cívico-Militares. Diário Oficial da União, Brasília, DF, Edição: 173, Seção: I, Página: I. Publicado em: 06 set. 2019.

BRASÍLIA. Lei Orgânica do Distrito Federal. Brasília, 8 jun. I993.

- Portaria Conjunta $n^{\circ}$ or de 31 de janeiro de 2019a. Dispõe sobre a implementação do projeto piloto Escola de Gestão Compartilhada, que prevê a transformação de quatro unidades específicas de ensino da rede pública do Distrito Federal em Colégios da Polícia Militar do Distrito Federal, e dá outras providências. Diário Oficial do Distrito Federal no 23 do dia or de fevereiro de 2019.

. Portaria Conjunta no 09, de I2 de setembro de 20I9b. Dispõe sobre a implementação do Projeto Escolas de Gestão Compartilhada, entre a Secretaria de Estado de Educação do Distrito Federal e a Secretaria de Estado de Segurança Pública do Distrito Federal, que prevê 
a transformação de Unidades Escolares específicas da Rede Pública de Ensino do Distrito Federal em Colégios Cívico-Militares do Distrito Federal, e dá outras providências. Diário Oficial do Distrito Federal no 207 do dia 30 de outubro de 2019.

- Regulamento Disciplinar dos Colégios Cívico-Militares do Distrito Federa, 2019c. Governo do Distrito Federal. Secretaria de Estado de Segurança Pública. Secretaria de Estado de Educação. Colégio Cívico-Militar do Distrito Federal. Regulamento Disciplinar. Brasília, 2019.

- MiNistériO PÚbliCO DA UNiÃO. Nota Técnica № oor/2org. PROEDUC/MPDFT. Posicionamento da PROEDUC, órgão de execução de defesa da educação do MPDFT, acerca da legalidade da política pública... Brasília: MPU; SEEDF; SSPDF, 3i jan. 2019.

CASTRO, Nicholas Moreira Borges de. "Pedagógico" e "Disciplinar": o Militarismo como prática de governo na educação pública do estado de Goiás. [manuscrito]: Castro, Nicholas Moreira Borges de. Orientador Prof. Daniel Schroeter Simião. Brasília, 2016.

COSTA, Ivone Freire. Polícia e sociedade. Gestão de segurança pública, violência e controle social. Salvador: EDUFBA, 2005.

DISTRITO FEDERAL. Projeto de Decreto Legislativo $n^{\circ}$ oo8/2019. Disponível em:http://leandrograss.com.br/wp-content/uploads/2019/o2/PDL-o8-2019-2.pdf. Acesso em 22 set. 2020 .

FREITAS, Luiz Carlos de. A reforma empresarial da educação: nova direita, velhas ideias. São Paulo: Expressão Popular, 2018.

FREUND, Julien. Sociologia de Max Weber. Trad. Luís Cláudio de Castro e Costa. 2. Rio de Janeiro: Forense, 1975.

GOVERNO DO DISTRITO FEDERAL. Currículo em movimento da educação básica pressupostos teóricos. Brasília, DF: Secretaria de Estado de Educação do Distrito Federal, 2014.

HÚNGARO, EDSON Marcelo. A questão do método na constituição da teoria social de Marx. In: CUNHA, C., VIEIRA DE SOUSA, J., SILVA, M. A. O método dialético na pesquisa em educação. Campinas, SP: Autores Associados, 2014.

LIBÂNEO. José Carlos. Democratização da Escola Pública: a pedagogia crítico-social dos conteúdos. São Paulo: Loyola, 1987. 
LOMBARDI, José Claudinei. Educação e ensino na obra de Marx e Engels. Campinas: Editora Alínea, 2oIr.

MALISKA, marcos Augusto. Max Eeber e o Estado Racional Moderno. Revista Eletrônica do CEJUR, v. I, n. I, ago./dez. 2006

MARX, Karl. A ideologia alemã. 9. São Paulo: Hucitec, 1993.

. O capital: o processo de produção do capital. Livro I, v. I. Rio de janeiro: Civilização Brasileira, 2006.

MINAYO, Maria Cecília de Souza. Violência e saúde. 2o. Rio de Janeiro: FIOCRUZ, 2006.

PINHEIRO, Paulo César. Polícia e consolidação democrática: o caso brasileiro. In: .et al. (Org.). São Paulo sem medo: um diagnóstico da violência urbana. Rio de Janeiro: Garamond, 1998.

RIBEIRO, Renata Lopes Silva. Fundamentos e práticas do colégio da polícia militar de Catalão: entre fardas, manuais e boletins. 2019. $190 \mathrm{f}$. Dissertação (Mestre em Educação) Universidade Federal de Goiás, Catalão, GO, 2009.

SANTOS, Rafael José da Costa. A militarização da escola pública em Goiás. [manuscrito]: Santos, Rafael José da Costa. Orientador Prof. Dr. Eduardo Sugizaki. 2016.

SAVIANI, Dermeval. O trabalho como princípio educativo frente às novas tecnologias. In: Ferreti, Celso J. et al. Novas tecnologias, trabalho e educação: um debate multidisciplinar. Petrópolis, RJ: Vozes, 1994, p. 151-168.

. Escola e democracia: teorias da educação, curvatura da vara, onze teses sobre educação e política. 32. São Paulo: Cortez/Autores Associados, 1999.

Associados, 20Ir.

. Pedagogia Histórico-crítica: primeiras aproximações. II. Campinas, SP: Autores

SOUZA, Candida de.; PAIVA, Ilana Lemos de. Faces da juventude brasileira: entre o ideal e o real. In: Estudos de Psicologia, Universidade Federal do Rio Grande do Norte, v. 17, n. 3, p. 353-36o, set./dez. 2012.

WEBER, Marx. Economia e sociedade: fundamentos da sociologia compreensiva. V.2, Brasília: UnB, 1999. 